\title{
Respostas fisiológicas de caprinos nativos mantidos em temperatura termoneutra e em estresse térmico
}

\author{
Luiz F. de A. Lucena', Dermeval A. Furtado², José W. B. do Nascimento ${ }^{2}$, \\ Ariosvaldo N. de Medeiros ${ }^{3}$ \& Bonifácio B. de Souza ${ }^{4}$
}

\begin{abstract}
RESUMO
Objetivou-se, com este trabalho, analisar as respostas fisiológicas de duas raças de caprinos nativos do semiárido brasileiro submetidos a ambiente com temperatura e umidade relativa controladas; utilizaramse 12 animais machos, 6 Canindés e 6 Moxotós, com pesos médios iniciais de 19,6 \pm 1,9 kg e 20,4 \pm $1,6 \mathrm{~kg}$, distribuídos em delineamento inteiramente casualizado em esquema fatorial $(2 \times 4)$, duas raças e quatro níveis de temperatura $\left(20,6,24,8,27,8\right.$ e $\left.31,6{ }^{\circ} \mathrm{C}\right)$, com 6 repetições, e umidade relativa média do ar de $60 \pm 5 \%$ e velocidade do vento de $0,5 \mathrm{~m} \mathrm{~s}^{-1}$. Na temperatura entre 20,6 e $27,8{ }^{\circ} \mathrm{C}$ a média da frequência respiratória $\left(25,7 \mathrm{mov} \mathrm{min}^{-1}\right)$ e frequência cardíaca $\left(76,7 \mathrm{mov} \mathrm{min}^{-1}\right)$ dos animais ficaram dentro da normalidade, sendo que a $31,6{ }^{\circ} \mathrm{C}$ ocorreu elevação da frequência respiratória $\left(134,5 \mathrm{mov} \mathrm{min}^{-1}\right)$ e da frequência cardíaca $\left(104,3\right.$ mov $\left.\mathrm{min}^{-1}\right)$. A temperatura retal foi semelhante em todas as temperaturas com média de $39,5^{\circ} \mathrm{C}$, dentro da faixa de normalidade para a espécie. A temperatura superficial elevou-se com o aumento da temperatura ambiente. A faixa de temperatura de 20,6 a $27,8{ }^{\circ} \mathrm{C}$ pode ser considerada a zona de conforto térmico para caprinos nativos Moxotó e Canindé.
\end{abstract}

Palavras-chave: caprinocultura, câmara climática, fisiologia animal

\section{Physiological responses of native goats maintained in thermoneutral temperature and thermal stress}

\begin{abstract}
The objective of this study was to determine the physiological response of two caprine races from the Brazilian semiarid, submitted to a controlled thermal conditions in a climatic chamber. Twelve male animals were used, 6 Canindés e 6 Moxotós, with mean weight of 19,6 $\pm 1,9 \mathrm{~kg}$ and 20,4 \pm 1,6 $\mathrm{kg}$ distributed in a completely randomized design, in factorial scheme $(2 \times 4)$, two races and four temperature levels $\left(20.6,24.8,27.8\right.$ and $\left.31,6^{\circ} \mathrm{C}\right)$, with six repetitions, with mean relative air humidity of $60 \pm 5 \%$ and wind speed of $0.5 \mathrm{~m} \mathrm{~s}^{-1}$. In the temperature between 20.6 and $27.8^{\circ} \mathrm{C}$ the mean respiratory frequency $(25.7 \mathrm{mov}$ $\left.\mathrm{min}^{-1}\right)$ and cardiac frequency $\left(76.7 \mathrm{mov} \mathrm{min}^{-1}\right)$ of the animals were within normality, however, at $31.6{ }^{\circ} \mathrm{C}$, occurred elevation to 134.5 and $104.3 \mathrm{mov} \mathrm{min}^{-1}$ for the respiratory and cardiac frequency, respectively. Rectal temperature was similar in all temperatures with average of $39.5{ }^{\circ} \mathrm{C}$, within the range of normality for the species. The superficial temperature raised with the increase of the environment temperature. The range of temperature between 20.6 and $27.8{ }^{\circ} \mathrm{C}$ can be considered within the thermal comfort zone for native Moxotó and Canindé caprines.
\end{abstract}

Key words: goat-raising, climatic chamber, animal physiology

\footnotetext{
' Unidade Acadêmica de Desenho Industrial/UFCG. Campus I. Avenida Aprígio Veloso, 882 - Bloco BO, CEP 58109-180, Campina Grande, PB. Fone: (83) 2101-1132. E-mail: lufelpe@gmail.com

2 UAEA/UFCG. CEP 58109-180, Campina Grande, PB. Fone: (83) 2101-1482 E-mail: dermeval@deag.ufcg.edu.br; wallace@deag.ufcg.edu.br

${ }^{3}$ Departamento de Zootecnia/CCA/UFPB. Campus II. Rodovia PB 079 - Km 12, CEP 58.397-000, Areia, PB. Fone: (83) 3362-2504. E-mail: ariosvaldo.medeiros@gmail.com

${ }^{4}$ DMV/UFCG. CEP 58700-970, Patos, PB. Fone: (83) 3511-3048. E-mail:bonifacio@pq.cnpq.br
} 


\section{INTRODUÇÃO}

Dentre os recursos genéticos disponíveis para produção animal em regiões áridas e semiáridas, enfatiza-se o potencial das raças caprinas nativas (Gomes et al., 2008) tendo-se como pressuposto teórico que os séculos de pressão de seleção natural promoveram elevado valor adaptativo em relação a esses ambientes, com expectativa de maior resistência às condições ambientais. Entre as raças nativas criadas e pesquisadas no semiárido brasileiro se destacam os Moxotó e Canindé, com estudos nas áreas de alimentação, manejo e adaptabilidade dessas raças a ambientes quentes salientando-se os índices produtivos (Santos et al., 2005; Souza et al., 2005; Ribeiro et al., 2006; Silva et al., 2006a,b,c; Furtado et al., 2008; Paulo et al.; 2008, Ribeiro et al., 2008; Souza et al., 2008b).

O estresse térmico é um dos fatores limitantes da produção caprina nos trópicos, principalmente no semiárido e para que esses animais mantenham a temperatura interna controlada, torna-se necessário o equilíbrio entre o ganho e a perda de calor. Atualmente, a referência fisiológica desta variável pode ser obtida mediante a temperatura retal, que pode variar nos caprinos adultos de 38,5 a 40,0 ${ }^{\circ} \mathrm{C}$ (Souza et al., 2008b; Pereira et al., 2011).

A temperatura retal é uma medida que expressa o desconforto animal diante de determinado ambiente, uma vez que representa a temperatura do núcleo central; é muito utilizada como critério de diagnóstico de doenças e para verificar o grau de adaptabilidade dos animais domésticos (Pereira et al., 2011).

Segundo Scarpellini \& Bícego (2010) animais homeotérmicos possuem mecanismos termorreguladores autonômicos que permitem ao organismo evitar variações em sua temperatura corporal, mesmo que a temperatura ambiente sofra grandes alterações. Entre esses mecanismos estão os de ganho (conservação e produção) e os de perda de energia, na forma de calor; tais mecanismos são controlados pelo sistema nervoso central, em especial por uma região que se situa na transição entre o diencéfalo e o telencéfalo, denominada área pré-óptica do hipotálamo anterior, que contém neurônios altamente especializados e com extrema sensibilidade ao calor, que aumentam suas atividades com o respectivo aumento da temperatura ambiente; logo, inibem os mecanismos de ganho e ativam os mecanismos de perda de energia, exercendo um importante papel integrador de todas as informações oriundas das várias regiões do organismo além de ser inerentemente sensível às alterações térmicas locais.

Furtado et al. (2008) mencionam, trabalhando a campo, que os caprinos da raça Moxotó, confinados e não confinados na região semiárida apresentaram, no período da tarde, considerado o mais quente do dia, uma frequência respiratória de $69,5 \mathrm{mov}$ $\mathrm{min}^{-1}$, valor este superior ao da manhã, de $62,6 \mathrm{mov} \mathrm{min}^{-1}$; Brasil et al. (2000) também verificaram, trabalhando com caprinos em condições de termo neutralidade e sob estresse térmico, variações na frequência respiratória com relação ao período do dia sendo a média no turno da tarde de $173,8 \mathrm{mov}^{-1} \mathrm{~min}^{-1}$, superior à do turno da manhã, de 80,0 mov $\min ^{-1}$.

De acordo com Fraser (1996) a frequência cardíaca média para caprinos é de 90 bat min $^{-1}$ podendo variar de 70 a 120 bat $\mathrm{min}^{-1}$. Silva et al. (2010) concluíram, trabalhando a campo com caprinos Moxotó realizando avaliações de adaptabilidade da raça ao semiárido, através de diversos parâmetros fisiológicos, entre eles a temperatura superficial (TS) que, nos turnos da manhã, tais animais possuíam médias de TS menor $\left(29,4{ }^{\circ} \mathrm{C}\right)$ ao compará-las com as do período da tarde $\left(31,3^{\circ} \mathrm{C}\right)$ fato este também confirmado por Souza et al. (2008b) que em trabalhos a campo verificaram na região semiárida brasileira, que a temperatura superficial média de caprinos $1 / 2$ Moxotó + $1 / 2$ SRD nos períodos da manhã e tarde foram de 27,2 e 31,6 ${ }^{\circ} \mathrm{C}$, respectivamente, sendo que esta elevação da temperatura superficial pode estar diretamente relacionada com a elevação da temperatura e com a diminuição da umidade relativa do ar.

Objetivou-se então, com este trabalho, a determinação das respostas fisiológicas de duas raças de caprinos nativos de regiões semiáridas, Moxotó e Canindé, ambas mantidas em ambiente com temperatura e umidade relativa do ar controladas, em situações de termo neutralidade e estresse térmico, submetidos ao confinamento em câmara climática.

\section{Material e Métodos}

Este experimento foi realizado nas dependências do Laboratório de Construções Rurais e Ambiência do Departamento de Engenharia Agrícola da Universidade Federal de Campina Grande, no período de outubro a dezembro de 2010, utilizandose câmara climática com $5,7 \mathrm{~m}^{2}$ de área construída e 2,6 m de pé-direito. A referida câmara era composta por sistemas de automação e controle de aquecimento, refrigeração, iluminação, ventilação, exaustão, umidificação, desumidificação e sala de monitoramento (Figura 1). Para cada animal foi disponibilizada uma área de $0,9 \mathrm{~m}^{2}$.

Utilizaram-se 12 caprinos nativos da região semiárida nordestina, todos machos e castrados da raça Moxotó e Canindé, sendo seis de cada grupo genético, com idades médias de seis meses e pesos médios de 17,3 $\pm 1,6$ e $16,6 \pm 1,9 \mathrm{~kg}$,

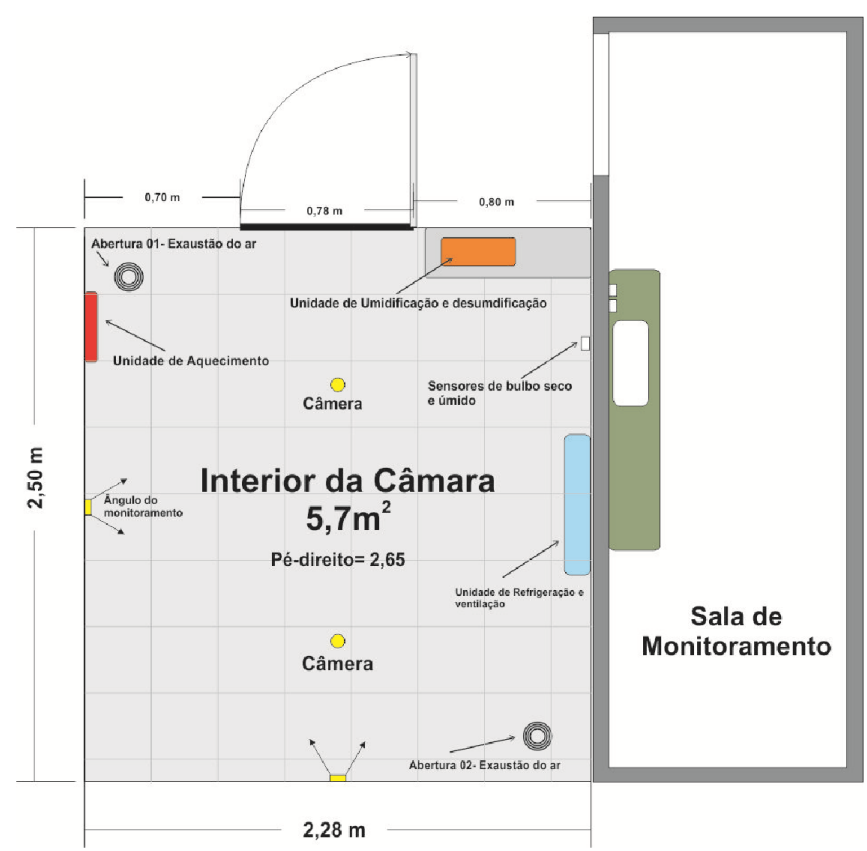

Figura 1. Disposição dos instrumentos no interior da câmara climática 
respectivamente. As variáveis climáticas temperatura ambiente e umidade relativa do ar foram coletadas automaticamente através de sensores de modelo MT-530 Super (Full Gauge Controls) localizados em pontos diversos no interior da câmara climática. As temperaturas do ar utilizadas na experimentação foram determinadas com base na zona de conforto térmico para caprinos, mencionados por Souza et al. (2008b), que se situa entre 20 e $30{ }^{\circ} \mathrm{C}$ e umidade relativa do ar, podendo variar entre 50 e $70 \%$.

As temperaturas ambientes médias obtidas no ambiente de estudo foram de, 20,$6 ; 24,8 ; 27,8$ e $31,6{ }^{\circ} \mathrm{C}$, com umidade relativa do ar em $60 \pm 5 \%$. Os animais foram submetidos a um período de quatro dias de adaptação às instalações e três dias de coleta, totalizando sete dias de experimentação para cada temperatura ambiente estudada totalizando, desta forma, 28 dias de experimentação para cada repetição. Em cada bloco experimental foram utilizados dois animais de cada raça, sendo que ao término de cada repetição, os animais eram retirados dando lugar a um novo grupo composto pelo mesmo quantitativo com características físicas semelhantes.

Cada animal foi mantido em baia individualizada, tendo acesso a ração e a água. Sobre o piso de cada baia foi utilizada uma placa de borracha com três centímetros de espessura contendo orifícios para escoamento de urina e fezes. Os animais ficaram confinados $24 \mathrm{~h}$ na câmara climática em todo o período experimental; para isto, utilizou-se o sistema 10/14, no qual permaneciam dez horas (das 8 às $18 \mathrm{~h}$ ) sob experimentação na condição ambiental objetivada e quatorze horas (das 18 às 8 h) em temperatura ambiente; no período das quatorze horas a câmara climática permanecia desligada e com a porta aberta.

A ração fornecida aos animais foi composta por feno de Tifton (Cynodon dactylon, (L) Pers) constituindo 43,0\% do volume total, farelo de milho $(26,6 \%)$, melaço $(2,5 \%)$, farelo de soja $(24,0 \%)$, óleo de soja (2,0\%), sal mineral $(1,5 \%)$ e calcário calcítico $(0,4 \%)$, composição esta de acordo com NRC (2007). $\mathrm{O}$ fornecimento da ração foi realizado duas vezes ao dia, às $7 \mathrm{e}$ $15 \mathrm{~h}$, sendo fornecido $0,5 \mathrm{~kg}$ em cada porção, totalizando $1 \mathrm{~kg}$ animal $\mathrm{dia}^{-1}$. O respectivo consumo foi quantificado pelo total fornecido subtraindo-se as sobras no período de $24 \mathrm{~h}$. A água foi fornecida em uma única porção de $2 \mathrm{~kg}$ por animal e, para sua quantificação, realizou-se o mesmo procedimento utilizado para o cálculo de consumo da ração.

As coletas dos dados foram realizadas três vezes ao dia $(9,13$ e $17 \mathrm{~h})$, sendo que em cada coleta eram obtidas a temperatura retal (TR), através de um termômetro clínico veterinário, introduzido no reto do animal por dois minutos, até que a temperatura se estabilizasse; a temperatura superficial do pelame (Tpelo) através do somatório das médias aritméticas da temperatura da fronte, do pescoço, do lombo, do costado, do ventre e da canela, com auxílio de um termômetro de infravermelho digital, cuja medida era expressa em graus centígrados; a temperatura superficial da pele (Tpele) através de raspagem de aproximadamente $4 \mathrm{~cm}^{2}$ de pelo da região do costado de cada animal obtendo-se, desta forma, a medida real da temperatura da pele; tal medição também foi realizada com auxílio de um termômetro de infravermelho digital.

A frequência respiratória (FR) foi obtida pela auscultação indireta das bulhas com auxílio de um estetoscópio flexível localizado na região laringo-traqueal, contando-se o número de movimentos durante $15 \mathrm{~s}$ e seu respectivo valor obtido multiplicado por quatro obtendo-se, desta forma, a FR em um minuto, expresso em mov $\mathrm{min}^{-1}$.

O procedimento para obtenção da frequência cardíaca (FC) foi realizado com o auxílio de um estetoscópio flexível, posto diretamente sobre a região torácica esquerda na altura aproximada do arco aórtico, contando-se o número de movimentos em $15 \mathrm{~s}$, sendo o valor coletado multiplicado por quatro, para determinação da frequência cardíaca em bat $\mathrm{min}^{-1}$. Realizou-se a categorização do estresse térmico apresentado pelos animais nas variáveis fisiológicas que apresentaram comportamentos significativamente alterados pela temperatura ambiente e umidade relativa do ar; para isto, utilizou-se o índice de temperatura e umidade (ITU) desenvolvido por Thom (1959) apresentada na Eq.1.

$$
\mathrm{ITU}=\mathrm{Tbs}+0,36 \mathrm{Tpo}+41,2
$$

em que:

Tbs - temperatura de bulbo seco, ${ }^{\circ} \mathrm{C}$

Tpo - temperatura do ponto de orvalho, ${ }^{\circ} \mathrm{C}$

Para os percentuais da categorização do estresse fisiológico foram levados em consideração os valores de conforto térmico citados por Baêta \& Souza (2010); valores até 74 definem situações de conforto térmico; valores entre 74 e 78 são considerados situação de alerta; de 79 a 84 , situação perigosa e acima de 84 situação de emergência, possuindo, como base, as médias de conforto fisiológico que cada variável apresentou ao longo das avaliações. O delineamento estatístico utilizado no trabalho foi o inteiramente casualizado com arranjo fatorial $2 \times 4$, sendo duas raças e quatro níveis de temperatura com seis repetições. Para composição do arquivo de dados, estudo descritivo das variáveis, análises de variância e verificação das pressuposições para as análises estatísticas, utilizou-se o programa computacional SAS (2006). As médias foram comparadas pelo teste de Turkey a 0,05 de significância.

\section{Resultados E Discussão}

Constatou-se forte correlação entre a temperatura do ar com todas as respostas fisiológicas apresentadas pelos animais (Tabela 1), fato também comprovado em estudos com caprinos Canindé e Moxotó, realizados por Furtado et al. (2008), Gomes et al. (2008), Paulo et al. (2008), Souza et al. (2008a,b) e Barreto et al. (2011) que evidenciaram respostas fisiológicas desses animais onde trabalhando a campo, evidenciaram a importância desta variável bioclimática. De acordo com as respostas obtidas pelos respectivos autores, verifica-se que a temperatura do ar é fator preponderante, tanto em experimentos a campo como em câmaras climáticas.

AFC e FR apresentaram correlação positiva com o aumento da temperatura, fato também comprovado em estudos a campo com caprinos Canindé e Moxotó realizados por Furtado et al. (2008), Gomes et al. (2008), Paulo et al. (2008), Souza et al. (2008 a,b) e Barreto et al. (2011) evidenciando a importância desta variável climática nas respostas fisiológicas desses 
Tabela 1. Resumo dos coeficientes de correlação e nível de significância referentes às variáveis frequência cardíaca $\left(\mathrm{FC}\right.$, bat $\left.\mathrm{min}^{-1}\right)$, frequência respiratória $\left(\mathrm{FR}, \mathrm{mov}^{\mathrm{min}}{ }^{-1}\right)$, temperatura da superfície do pelo $\left(\right.$ Tpelo, $\left.{ }^{\circ} \mathrm{C}\right)$, temperatura da pele $\left(\right.$ Tpele, $\left.{ }^{\circ} \mathrm{C}\right)$ e temperatura retal $\left(\mathrm{TR}^{\circ}{ }^{\circ} \mathrm{C}\right)$

\begin{tabular}{|c|c|c|c|c|c|c|c|}
\hline & Temp. & Umid. & $\overline{F C}$ & FR & Tpelo & Tpele & TR \\
\hline Temp. & - & $-0,72394<0,0001$ & $0,77418<0,0001$ & $0,77582<0,0001$ & $0,97002<0,0001$ & $0,82725<0,0001$ & $0,57207<0,0001$ \\
\hline Umid. & & & $-0,53538<0,0010$ & $-0,62192<0,0001$ & $-0,77022<0,0001$ & $-0,54824<0,0001$ & $-0,54322<0,0001$ \\
\hline $\mathrm{FC}$ & & & & $0,92207<0,0001$ & $0,75408<0,0001$ & $0,54457<0,0001$ & $0,74409<0,0001$ \\
\hline FR & & & & & $0,75445<0,0001$ & $0,54627<0,0001$ & $0,78036<0,0001$ \\
\hline Tpelo & & & & & & $0,83517<0,0001$ & $0,54405<0,0001$ \\
\hline Tpele & & & & & & & $0,39750<0,0051$ \\
\hline TR & & & & & & & - \\
\hline
\end{tabular}

animais; porém, mesmo com forte correlação positiva com a $\mathrm{FC}, \mathrm{FR}, \mathrm{T}_{\text {pelo }}$ e $\mathrm{T}_{\text {pele }}$, nota-se que a temperatura ambiente não apresenta forte correlação com a TR dos animais. Este dado denota que os animais se utilizaram da FC e FR como elementos prioritários para o controle e manutenção da TR fisiológica em níveis adequados à espécie mostrando, ainda, que esses animais se encontram bem adaptados ao calor pelo fato da TR não ter sido influenciada significativamente pela temperatura do ar.

A umidade relativa do ar apresentou-se com uma correlação negativa entre todas as variáveis em estudo (Tabela 1). Nota-se, ao correlacionar as variáveis fisiológicas FR e FC, que ambas se apresentaram com alto nível de correlação $(0,92)$ denotando que se encontraram sincronizadas em prol da manutenção, por exemplo, da TR fisiológica; outro fator evidenciado é que as FC e FR se apresentam com valores muito semelhantes ao serem correlacionadas com a temperatura ambiente, reforçando o forte sincronismo dessas duas variáveis fisiológicas.

Verifica-se que não houve efeito $(\mathrm{P}<0,05)$ da raça para nenhum das variáveis fisiológicas estudadas (Tabela 2); esses dados demonstram que, pelo fato dos animais da raça Canindé e Moxotó serem oriundos de regiões semiáridas, onde foram submetidos a processos adaptativos semelhantes, a exteriorização das variáveis fisiológicas também é semelhante. Tais similaridades foram verificadas por Barreto et al. (2011) em pesquisas com essas mesmas raças ao verificarem, também, semelhanças comportamentais com relação às variáveis fisiológicas TR e FR. Ribeiro et al. (2006) comentam que as semelhanças produtivas entre Canindé e Moxotó são mais evidenciadas na fase adulta quando adquirem tamanho corporal semelhante.
A frequência cardíaca (FC) apresentada pelos animais (Tabela 2) foi de 83,6 bat $\mathrm{min}^{-1}$, valor este considerado normal para a espécie. Segundo Fraser (1996) a referida variável deve

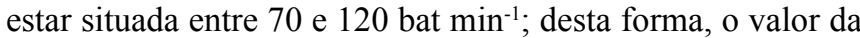
FC de 83,6 bat $\mathrm{min}^{-1}$ verificado neste trabalho se assemelha ao verificado por Souza et al. (2005) que, trabalhando com caprinos nativos na região semiárida do nordeste, a campo, com temperatura média de $25^{\circ} \mathrm{C}$ e UR de $51 \%$, verificaram que os animais apresentaram, em média, uma FC de 83 bat min $^{-1}$, valor também considerado normal para a espécie.

Ao analisar as temperaturas ambientes de maneira isoladas (Tabela 2) verifica-se que a FC, mesmo apresentando um ligeiro acréscimo de 6,0 bat $\mathrm{min}^{-1}$, entre a temperatura de 20,6 com UR média $_{\text {de }} 61,4 \%$ e $24,8^{\circ} \mathrm{C}$ com UR média $_{\text {de }} 63,5 \%$, a $\mathrm{FC}_{\text {média }}$ passou de 72,8 para 78,9 bat $\mathrm{min}^{-1}$. Entre 24,8 e 27,8 ${ }^{\circ} \mathrm{C}$ a FC também não apresentou diferença significativa $(\mathrm{P}>$ 0,05 ) obtendo-se, nos três primeiros níveis, média de 76,7 \pm 5 bat minn $^{-1}$ porém estas diferiram da TA de $31,6{ }^{\circ} \mathrm{C}$ e UR de $57,9 \%$, sendo que as três primeiras temperaturas podem ser consideradas dentro da zona de conforto térmico para esses animais (Souza et al., 2008b).

Souza et al. (2005) mencionam, trabalhando a campo, que em temperatura ambiente de $25{ }^{\circ} \mathrm{C}$ e UR média de $51 \%$, os caprinos Moxotó apresentam em média uma FC de 121 bat $\mathrm{min}^{-1}$, valor acima do verificado neste trabalho cuja temperatura ambiente média foi de $24,8^{\circ} \mathrm{C}$ e UR média de $63,5 \%$, os animais apresentaram uma FC de 78,9 bat min $^{-1}$. Esta discrepância na comparação dos dados se deve, provavelmente,à umidade relativa do ar, tendo havido uma variação, neste caso de $12,5 \%$ a mais em relação às condições de umidade relatadas por Souza et

Tabela 2. Valores médios e desvios-padrão referentes aos níveis dos fatores raça e temperatura das variáveis frequência cardíaca (FC), frequência respiratória (FR), temperatura da superfície do pelame (Tpelo), temperatura da pele (Tpele) e temperatura retal (TR)

\begin{tabular}{|c|c|c|c|c|c|}
\hline \multirow{3}{*}{ Fatores } & \multicolumn{5}{|c|}{ Variáveis fisiológicas } \\
\hline & \multirow{2}{*}{$\begin{array}{c}\text { FC } \\
\text { bat } \text { min }^{-1}\end{array}$} & \multirow{2}{*}{$\begin{array}{c}\text { FR } \\
\text { mov } \text { min }^{-1}\end{array}$} & Tpelo & Tpele & TR \\
\hline & & & \multicolumn{3}{|c|}{${ }^{\circ} \mathrm{C}$} \\
\hline \multicolumn{6}{|l|}{ Raça (R) } \\
\hline Canindé & $84,0 \pm 13,8 a$ & $53,5 \pm 50,3 a$ & $28,0 \pm 4,0 \mathrm{a}$ & $31,1 \pm 3,4 a$ & $39,55 \pm 0,1 a$ \\
\hline Moxotó & $83,1 \pm 13,9 a$ & $52,4 \pm 48,5 a$ & $28,5 \pm 4,0 a$ & $31,8 \pm 3,7 a$ & $39,52 \pm 0,2 a$ \\
\hline Média Geral & 83,6 & 52,9 & 28,2 & 31,52 & 39,5 \\
\hline \multicolumn{6}{|l|}{ Temperatura $\left({ }^{\circ} \mathrm{C}\right)$ e UR\% } \\
\hline $20,6 / \mathrm{UR}_{\text {média }}=61,4$ & $72,8 \pm 3,2 b$ & $24,0 \pm 2,2 b$ & $23,0 \pm 0,9 d$ & $26,9 \pm 2,2 \mathrm{c}$ & $39,4 \pm 0,1 \mathrm{a}$ \\
\hline $24,8 /$ UR $_{\text {média }}=63,5$ & $78,9 \pm 5,5 b$ & $24,1 \pm 1,5 b$ & $26,2 \pm 1,0 \mathrm{c}$ & $31,1 \pm 2,9 b$ & $39,4 \pm 0,1 \mathrm{a}$ \\
\hline $27,8 \mathrm{UR}_{\text {média }}=58,4$ & $78,4 \pm 4,2 b$ & $29,0 \pm 4,5 b$ & $30,2 \pm 1,1 b$ & $33,3 \pm 0,9 a$ & $39,4 \pm 0,1 \mathrm{a}$ \\
\hline $31,6 / \mathrm{UR}_{\text {média }}=57,9$ & $104,2 \pm 10,2 \mathrm{a}$ & $134,7 \pm 21,3 a$ & $33,4 \pm 0,3 a$ & $34,7 \pm 0,4 a$ & $39,7 \pm 0,1 a$ \\
\hline
\end{tabular}

Médias seguidas pelas mesmas letras dentro de cada coluna não diferem estatisticamente entre si pelo teste de Tukeya 0,05 de probabilidade 
al. (2005); referida discrepância é devida, também, às condições ambientais nas quais os experimentos foram realizados, ou seja, apesar de serem animais de mesma raça as variáveis, manejo alimentar e fisiologia, podem interferir nos resultados.

Verifica-se um comportamento relativamente harmônico em relação aos batimentos cardíacos no decorrer dos três primeiros estágios de temperaturas (Figura 2), porém na transição entre a temperatura ambiente de 27,8 para $31,6^{\circ} \mathrm{C}$, a $\mathrm{FC}$ média foi elevada de 74 para 115 bat min $^{-1}$ atingindo o valor máximo de 118 bat min $^{-1}$ apresentando uma amplitude, neste intervalo de temperatura, de 44 bat min $^{-1}$ situação em que os animais se apresentaram em estado ofegante, deitados, letárgicos, com cabeça baixa e os membros frontais estirados no piso, como tentativa de eliminação do excesso de calor através de trocas térmicas com o piso, que era emborrachado.

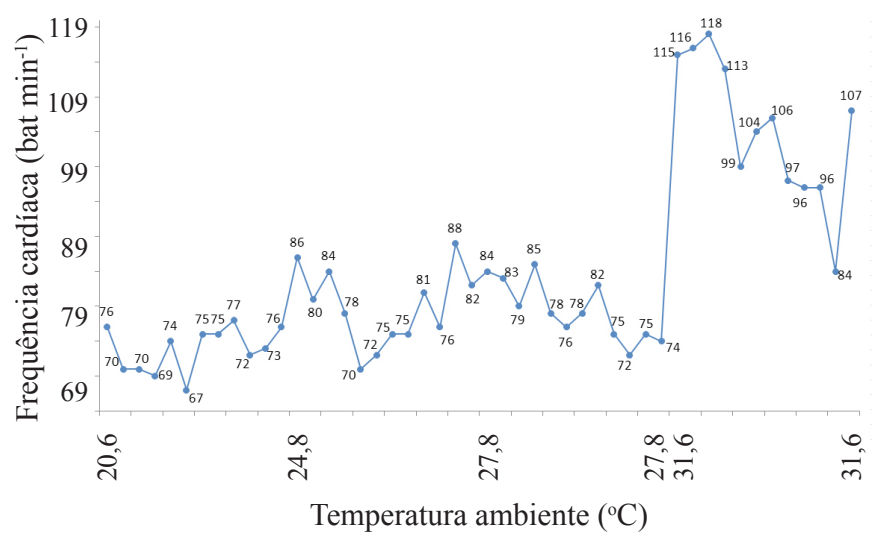

Figura 2. Comportamento da frequência cardíaca ao longo do período experimental nas quatro temperaturas ambientais avaliadas

Souza et al. (2010) observaram, em experimentos com caprinos a campo, que os animais apresentam valores de 122 bat $\mathrm{min}^{-1}$ para FC a uma temperatura média do ar de $40,8^{\circ} \mathrm{C}$; nas condições avaliadas neste experimento os animais apresentaram uma FC máxima de 118 bat $\mathrm{min}^{-1} \mathrm{com}$ temperatura média de $31,6{ }^{\circ} \mathrm{C}$; no entanto, o fator de diferenciação comportamental dos animais entre os experimentos se deve às características climáticas internas de uma câmara, em que há grande saturação de ar aquecido em temperaturas médias de $32{ }^{\circ} \mathrm{C}$ e baixa capacidade de renovação do ar ao comparar com experimentos a campo.

Através das médias fisiológicas $\left(76\right.$ bat $\left.\mathrm{min}^{-1}\right)$ e respectivo desvio padrão $\left( \pm 5\right.$ bat min $\left.^{-1}\right)$ os animais podem ser considerados dentro da faixa de conforto $\mathrm{FC}_{\text {conforto }}$, até o valor de 81 bat min $^{-1}$ sendo que valores acima deste são considerados estresse térmico. Observa-se que os animais elevaram a FC (Figura 2) no início do estresse térmico $\left(115,116\right.$ e 118 bat min $\left.^{-1}\right)$ mesmo que se tenha verificado, posteriormente, uma reação fisiológica por parte dos animais na redução desta variável, ou seja, foram ativados outros mecanismos de termorregulação corporal ou de adaptação a esta nova temperatura; apesar disto, esses mecanismos não foram suficientes para diminuir a FC às médias anteriores, demonstrando que os animais conseguem ajustar-se ao estresse térmico por períodos curtos em temperaturas acima da ZCT.

$\mathrm{O}$ índice de temperatura e umidade (ITU) apresentado foi de 76,1, quando os animais apresentaram a $\mathrm{FC}_{\text {conforto }}$ de 81 bat $\min ^{-1}$ considerado situação de alerta, conforme Baêta \& Souza
(2010); entretanto, os caprinos não apresentaram alterações significativas nesta variável. O ITU máximo atingido foi de 81,7 , com uma TA de $31,6^{\circ} \mathrm{C}$ condições nas quais os animais apresentaram $\mathrm{FC}$ de 121 bat min $^{-1}$ haja vista que se encontravam em estado de desconforto térmico.

Ao longo da avaliação comportamental da FC com relação às temperaturas ambiente estudadas, verificou-se que a APO (área pré-óptica do hipotálamo anterior) mencionada por Scarpellini \& Bícego (2010) foi acionada quando a temperatura ambiente atingiu $31,6^{\circ} \mathrm{C}$ (Figura 1), sendo esta utilização uma tentativa de regularização da temperatura corporal para a manutenção da $\mathrm{FC}_{\text {conforto }}$, mas se verificou, ainda que, após atingir o pico máximo de 118 mov min ${ }^{-1}$, a $\mathrm{FC}$ interferiu nos mecanismos termorregulatórios referentes à $\mathrm{APO}$, uma vez que a $\mathrm{FC}$ não atinge mais os valores ideais pois, quando a temperatura ambiente ultrapassa em demasia as zonas de conforto térmico dos animais homeotérmicos, os mecanismos hipotalâmicos de controle térmico não conseguem mais administrar com eficiência a eliminação do excesso de calor, o que se caracteriza por quadros de hipertermia.

As médias da FR apresentadas pelos animais (Tabela 2) não diferiram estatisticamente $(\mathrm{P}>0,05)$ quando submetidos às temperaturas entre $20,6 \mathrm{e} 27,8^{\circ} \mathrm{C}$; mesmo assim, todas elas diferiram da TA de $31,6^{\circ} \mathrm{C}$, semelhante ao ocorrido com a FC. Nas três primeiras temperaturas a FR média oscilou de $24 \pm 2,21$ a $29 \pm 4,5$, média de $26,5 \pm 3,4$ considerada, portanto, normal para a espécie (Gomes et al., 2008) passando a 134,7 $\pm 21,3$ mov $\min ^{-1}$ a $31,6^{\circ} \mathrm{C}$ (Figura 3 ) caracterizando estresse térmico para os animais que utilizaram esta variável fisiológica como mecanismo de perda de calor visto que, de acordo com Silva et al. (2006b) quando a FR se apresenta acima da considerada fisiológica para a espécie, com temperatura ambiente elevada, os animais ativam o sistema termorregulatório promovendo maior perda de calor, pela forma insensível, ou seja, através da respiração e da sudorese.

Nas temperaturas compreendidas entre 20,6 e $27,8^{\circ} \mathrm{C}$, os animais se apresentaram em estado de eupneia (Figura 3 ) com movimentos suaves do flanco; em contrapartida, apresentaram taquipneia constante a $31,6{ }^{\circ} \mathrm{C}$, ao se observar outros mecanismos fisiológicos de perda de calor, como dilatação das mucosas das narinas e movimentação da laringe para ampliação das entrada do ar visando a um abastecimento pulmonar eficaz. Mesmo com a notória capacidade de termorregulação térmica inata aos Canindés e Moxotós em situações de hipertermia observou-se que o pico máximo apresentado foi de $170 \mathrm{mov}$ min $^{-1}$ (Figura 3) permanecendo posteriormente com média de134 $\mathrm{mov}^{\mathrm{min}^{-1}}$.

Este comportamento se manteve semelhante ao da FC, mostrando que tais variáveis possuem uma relação intrínseca ao serem submetidas a amplitudes térmicas elevadas. Este comportamento da possível incapacidade de redução da FR máxima aos níveis da $\mathrm{FR}_{\text {conforto }}$ pode ser explicado pelo fato de que, à medida em que ocorre elevação da temperatura ambiente, a eficiência da perda de calor sensível diminui em razão do menor gradiente de temperatura entre a pele do animal e a do ambiente (Souza et al., 2008) e nessas situações o animal pode manter a temperatura corporal por meio de vaso dilatação, que aumenta o fluxo sanguíneo periférico e a temperatura 


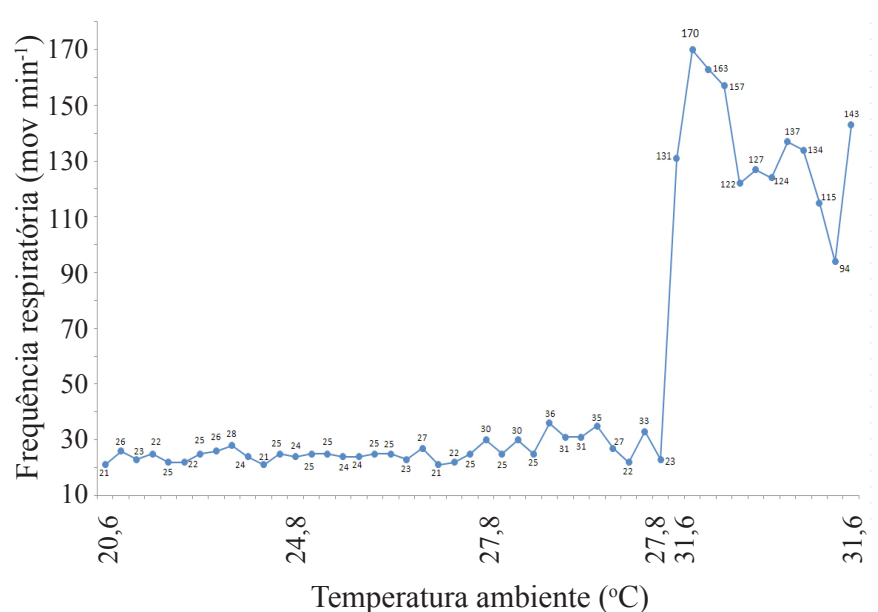

Figura 3. Comportamento da frequência respiratória ao longo do período experimental nas temperaturas avaliadas

da pele; no entanto, se a temperatura ambiente continuar a elevar-se o animal passará, então, a depender da perda de calor por evaporação, através da respiração e/ou sudorese. Correlacionado o ITU com a temperatura ambiente e frequência respiratória, observa-se que a $28,1{ }^{\circ} \mathrm{C}$ e FR de 35 mov min $^{-1}$, o ITU foi de 76,5 , valor este categorizado na situação de estresse fisiológico de alerta, conforme Baêta \& Souza (2010) e com o ITU de 81,2 (TA de $31,6^{\circ} \mathrm{C}$ ) a FR média foi de 134 mov min $^{-1}$.

Apesar da pelagem ser composta por pelos grossos, laníferos e escuros dos Canindés, com relação aos pelos grossos, claros e sem camadas de lã dos Moxotós, não foram evidenciadas diferenças significativas $(P>0,05)$ para a temperatura superficial na pele e no pelo, obtendo-se médias gerais de 28,2 e $31,5^{\circ} \mathrm{C}$, respectivamente, nas diferentes temperaturas. Esses dados discordam das citações de Silva et al. (2001) que, trabalhando a campo, relataram que os animais com pelagem escura estão mais sujeitos ao estresse calórico ao compará-los com animais de pelagem clara; o fato é que, nas condições de campo, o efeito da radiação é elevado enquanto em câmaras climáticas este fator se torna reduzido, fazendo com que a cor da pelagem em condições de estresse térmico dos animais, mas com baixa radiação solar se torne quase nulo pois a superioridade das pelagens claras sobre as negras ocorre pelo fato das mesmas refletirem mais.

Ao correlacionar as temperaturas do pelame com a da pele, nota-se que a dinâmica geral do aumento foi semelhante em cada estágio de temperatura (Figura 4). Presume-se que nas temperaturas do ar compreendidas entre 20,6 e $27,8^{\circ} \mathrm{C}$ os animais utilizam a vasodilatação periférica como técnica de resfriamento de maneira constante e de forma eficiente, representado pela grande amplitude dos pontos médios; verificou-se, porém, que na medida em que a temperatura do ar aumentava os gradientes térmicos diminuíam, a ponto da pele não conseguir mais realizar as devidas trocas de calor de maneira eficiente ao se aproximar da temperatura de $31,6{ }^{\circ} \mathrm{C}$. Desta forma, o calor endógeno ficou impossibilitado de ser liberado pelos mecanismos dissipadores ocasionando efeitos sistêmicos negativos ao organismo.

Souza et al. (2005) comentam que em ambientes com temperaturas elevadas a eficiência de perda de calor do

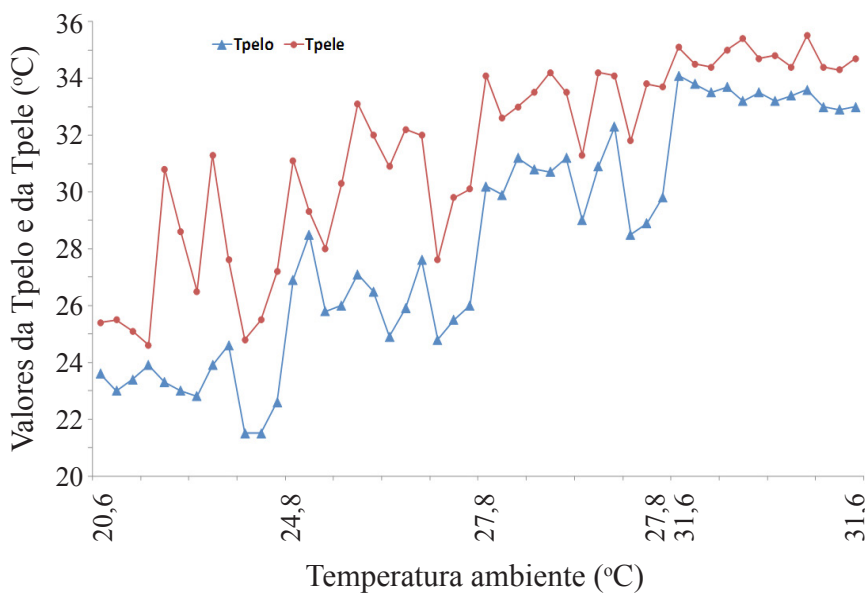

Figura 4. Comparação dos comportamentos da temperatura do pelame (Tpelo) e da pele (Tpele) ao longo do período experimental nas quatro temperaturas ambiente estudadas

animal para o meio diminui em razão do menor gradiente de temperatura entre a pele do animal e a do ambiente. $\mathrm{Na}$ temperatura de $20,6{ }^{\circ} \mathrm{C}$ o gradiente térmico (Tpele - Tar) é de $6,3{ }^{\circ} \mathrm{C}$, salientando a boa capacidade de termorregulação dos animais em temperaturas dentro do limite da zona crítica inferiorem que, através do centro de termorregulação hipotalâmica, aumentam a vazão sanguínea na pele, ativando os mecanismos de vasodilatação periférica transferindo o calor gerado internamente para a pele, com o objetivo de ser eliminado pelo processo de perda de calor sensível; logo, notase a boa utilização dos mecanismo de termorregulação pelos animais mediante a elevação da temperatura, principalmente na transição entre a temperatura ambiente de 27,8 para $31,6^{\circ} \mathrm{C}$.

Houve forte interação entre a variável Tpelo com as variáveis FC e FR (Tabela 3). A Tpelo, que por sua vez é diretamente influenciada pela temperatura do ar (Tar), altera significativamente $(\mathrm{P}>0,05)$ a FC e FR; verifica-se, entretanto, que as variáveis Tpelo e Tpele possuem coeficientes de correlação mais baixos com relação à TR dos animais evidenciando, com isto, a grande capacidade de homeotermia e manutenção da TR fisiológica. O gradiente térmico apresentado pela pele (Tpele - Tar) nas temperaturas ambiente de 20,6; 24,8 e $27,8^{\circ} \mathrm{C}$ (Tabela 3) apresentaram uma média de $6,1^{\circ} \mathrm{C}$, respectivamente, porém na temperatura ambiente de $31,6^{\circ} \mathrm{C}$ a temperatura da pele se aproxima da temperatura ambiental dificultando a troca de calor por radiação, condução e convecção ocasionando, nos animais, sinais de estresse térmico com picos máximos de desconforto cardíaco (FC) e respiratório (FR) além de comportamentais ao atingir o gradiente de $3,16^{\circ} \mathrm{C}$ entre a temperatura da pele e do ambiente, embora a TR se tenha mantido estável, mesmo com oscilações da Tpelo e Tpele.

A temperatura retal dos animais não apresentou diferenças significativas $(\mathrm{P}>0,05)$ entre as raças, com valores médios de $39,5 \pm 0,16{ }^{\circ} \mathrm{C}$ e $39,5 \pm 0,2{ }^{\circ} \mathrm{C}$ para o Canindé e Moxotó respectivamente, média de $39,5 \pm 0,18^{\circ} \mathrm{C}$. Entre as diferentes temperaturas verifica-se o mesmo comportamento e esta temperatura pode ser caracterizada como dentro da normalidade para a espécie. Santos et al. (2005), Furtado et al. (2008) e Gomes et al. (2008) observaram, em trabalhos 
Tabela 3. Valores médios, desvio padrão das variáveis temperaturas do pelo(Tpelo, $\left.{ }^{\circ} \mathrm{C}\right)$ e temperatura da pele $(\mathrm{Tpele}$,

${ }^{\circ} \mathrm{C}$ ) e gradientes térmicos dos caprinos em função da raça e da temperatura ambiente

\begin{tabular}{|c|c|c|c|c|c|}
\hline \multirow{2}{*}{$\begin{array}{l}\text { Temperatura } \\
\text { ambiente (T) }\end{array}$} & Tpelo & Tpele & \multicolumn{3}{|c|}{ Grad. térmico } \\
\hline & & & $($ Tpelo - T) & $($ Tpele - T) & (Tpelo - Tpele) \\
\hline 20,6 & $23,0 \pm 0,92 d$ & $26,9 \pm 2,28 c$ & 2,49 & 6,30 & $3,81^{\circ}$ \\
\hline 24,8 & $26,2 \pm 1,08 c$ & $31,1 \pm 2,99 b$ & 1,49 & 6,32 & 4,83 \\
\hline 27,8 & $30,2 \pm 1,11 b$ & $33,3 \pm 0,96 a$ & 2,48 & 5,51 & 3,03 \\
\hline 31,6 & $33,4 \pm 0,36 \mathrm{a}$ & $34,7 \pm 0,40 \mathrm{a}$ & 1,80 & 3,16 & 1,36 \\
\hline
\end{tabular}

Médias seguidas pelas mesmas letras dentro de cada fator não diferem estatisticamente entre si pelo teste de Tukey, a 0,05 de probabilidade

com caprinos na região semiárida nordestina, que mesmo sob estresse térmico os animais apresentaram uma TR média de $39,5^{\circ} \mathrm{C}$, ou seja, dentro, portanto, da média normal para a espécie que, segundo Kolb et al. (1987) a TR fisiológica média normal de um caprino adulto é de $39,5^{\circ} \mathrm{C}$, podendo haver oscilações na faixa de 38,5 a $40,5^{\circ} \mathrm{C}$.

Para Pereira et al. (2011) a temperatura retal pode ser a medida que expressa o desconforto animal diante de determinado ambiente representando a temperatura do núcleo central dos animais, sendo muito utilizada como critério de diagnóstico de doenças e para verificar o grau de adaptabilidade dos animais domésticos. Portanto, observa-se que os animais avaliados neste trabalho se mostraram bem adaptados ao serem submetidos a temperaturas elevadas pois mantiveram a temperatura retal dentro da normalidade; contudo,elevaram a FC ao pico máximo de 118 bat $\mathrm{min}^{-1}$ e FR a 170 mov min ${ }^{-1}$ bem como se utilizaram da elevação da temperatura da pele e pelame como mecanismos de dissipação do excesso de calor.

\section{Conclusões}

1. As temperaturas de 20,6 a $27,8{ }^{\circ} \mathrm{C}$ podem ser consideradas dentro da zona de conforto térmico para os animais estudados.

2. Em temperaturas de $31,6{ }^{\circ} \mathrm{C}$, os animais elevaram a frequência cardíaca e respiratória e a temperatura da pele, caracterizando situação de estresse térmico.

3. A frequência cardíaca e a respiratória constituem as variáveis mais afetadas nos animais quando mantidos sob estresse térmico.

4. O índice de temperatura e umidade (ITU) acima de 81,3 pode ser considerado estressante para caprinos das raças Canindé e Moxotó.

\section{Literatura Citada}

Baêta, F. C.; Souza, C. F. Ambiência em edificações rurais: Conforto animal. 2.ed. Viçosa: UFV, 2010. 269p.

Barreto, L. M. G.; Medeiros, A. N. de; Batista, A. M. V; Furtado, D. A.; Araújo, G. G. L. de; Lisboa, A. C. C.; Paulo, J. L. de A.; Souza, C. M. S. de. Comportamento ingestivo de caprinos das raças Moxotó e Canindé em confinamento recebendo dois níveis de energia na dieta. Revista Brasileira de Zootecnia, v.40, p.834-842, 2011.

Brasil, L. H. de A.; Wechesler, F. S.; Júnior, F. B.; Gonçalves, H.C.; Bonassi, I. A. Efeitos do estresse térmico sobre a produção, composição química do leite e respostas termorreguladoras de cabras da raça alpina. Revista Brasileira de Zootecnia, v.29, p.1632-1641, 2000.
Fraser, C. M. Manual merck de veterinária: Um manual de diagnóstico, tratamento, prevenção e controle de doenças para o veterinário. São Paulo: Roca, 1996. 2.169p.

Furtado, D. A.; Gomes, C. A. V.; Medeiros, A. N. de; PimentaFilho, E. C.; Lima Júnior, V. de L. Efeito do ambiente térmico e suplementação nas variáveis fisiológicas de caprinos moxotó em confinamento e semiconfinamento. Engenharia Agrícola, v.28, p.396-405, 2008.

Gomes, C. A. V.; Furtado, D. A.; Medeiros, A. N de.;Pimenta Filho, E. C.; Lima Júnior, V. de L. Efeito do ambiente térmico e níveis de suplementação nos parâmetros fisiológicos de caprinos Moxotó. Revista Brasileira de Engenharia Agrícola e Ambiental, v.12, p.213-219, 2008.

Kolb, E. Fisiologia veterinária. Rio de Janeiro: Guanabara Koogan, 4.ed. 1987.612p.

NRC - National Research Council. Nutrient requirements of small ruminants: Sheep, goats, cervids, and new world camelids. Washington: National Academy Press, 2007. $362 p$.

Paulo, J. L. A.; Furtado, D. A.; Medeiros, A. N de.; Barreto, L. M. G.; Lisboa, A. C. C. Avaliação dos parâmetros fisiológicos de caprinos da raça canindé e Moxotó confinados no semiárido paraibano. Congresso Brasileiro de Zootecnia, 2008, João Pessoa. Anais.... João Pessoa: Associação Brasileira de Zootecnia, 2008,CD-Rom

Pereira, G.M.; Souza, B. B. de; Silva,A. M. de A.; Roberto, J. V. B.; Silva, C. M. B. de A. Avaliação do comportamento fisiológico de caprinos da raça saanen no semiárido paraibano. Revista Verde de Agrotecnologia e Desenvolvimento Sustentável, v.6, p.83-88, 2011.

Ribeiro, N. L.; Furtado, D. A.; Medeiros, A. N. de.; Ribeiro, M. N..; Silva, R. C. B.; Souza, C. M. S. Avaliação dos índices de conforto térmico, parâmetros fisiológicos e gradiente térmico de ovinos nativos. Engenharia Agrícola, v.28, p.614-623, 2008.

Ribeiro, V. L.; Batista, A. M. V.; Carvalho, F. F. R. de; Azevedo, M. de.; Mattos, C. W.; Alves, K. S. Comportamento ingestivo de caprinos Moxotó e Canindé submetidos à alimentação à vontade e restrita. Acta Science Animal Science, v.28, p.331-337, 2006.

Santos, F. C. B. dos; Souza, B. B. de.;Alfaro, C. E. P.; Cézar, M. F.; Pimenta Filho, E. C.; Acosta, A. A. A.; Santos, J. R. S. dos. Adaptabilidade de caprinos exóticos e naturalizados ao clima semiárido do Nordeste brasileiro. Ciência e Agrotecnologia, v.29, p.142-149, 2005.

SAS. SAS 9.1 for windows. Cary: SAS Inc; 2006.

Scarpellini, C. da S.; Bícego, K. C. Regulação da temperatura corporal em diferentes estados térmicos: Enfase na anapirexia. Revista da Biologia, v.5, p.1-6, 2010. 
Silva, E. M. N da.; Silva, G. de A.; Cezar, M. F.; Souza, W. H. de.; Benício, T. M. A.; Freitas, M. M. S. da. Avaliação da adaptabilidade de caprinos exóticos e nativos no semiárido paraibano. Ciência e Agrotecnologia, v.30, p.516-52, 2006 a.

Silva, E. M. N. da; Souza, B. B. de.; Sousa, O. B de; Silva, G. de A.; Freitas, M. M. S. de. Avaliação da adaptabilidade de caprinos ao semiárido através de parâmetros fisiológicos e estruturas do tegumento. Revista Caatinga, v.23, p.142-148, 2010.

Silva, G. de A.; Souza, B. B. de; Alfaro, C. E. P.; Azevedo Neto, J.; Azevedo, S .A.; Silva, E. M. N da.; Silva, R. M. N. da. Influência da dieta com diferentes níveis de lipídeo e proteína na resposta fisiológica e hematológica de reprodutores caprinos sob estresse térmico. Ciência e Agrotecnologia, v.30, p.54-161, 2006b.

Silva, G. de A.; Souza, B. B. de; Alfaro, C. E. P.; Silva, E. M. N da; Azevedo, S. A.; Azevedo Neto, J.; Silva, R. M. N. da. Efeito da época do ano e período do dia sobre os parâmetros fisiológicos de reprodutores caprinos no semiárido paraibano. Revista Brasileira de Engenharia Agrícola e Ambiental, v.10, p.903-909, 2006c.

Silva. R. G. da; Scala, N. L. J.; BersiPocay, P. L. Transmissão de radiação ultravioleta através do pelame e da epiderme de bovinos. Revista Brasileira de Zootecnia, v.30, p.1939-1947, 2001.
Souza, B. B. de.; Souza, E. D. de; Cezar, M. F.; Souza, W. H. de; Santos, J. R. S. dos; Benicio, T. M. A. Temperatura superficial e índice de tolerância ao calor de caprinos de diferentes grupos raciais no semi-árido nordestino. Ciência e Agrotecnologia, v.32, p.275-280, 2008a.

Souza, B. B. de; Souza, E. D. de; Silva. R. M. N. da; Cezar, M. F.; Santos, J. R. S. dos; Silva, G. de A. Respostas fisiológicas de caprinos de diferentes grupos genéticos no semi-árido paraibano. Ciência e Agrotecnologia, v.32, p.314-320, 2008b.

Souza, E. D. de; Souza, B. B. de; Souza, W. H. de.; Cezar, M. F.; Santos, J. R. S. dos; Tavares, G. de P.; Determinação dos parâmetros fisiológicos e gradiente térmico de diferentes grupos genéticos de caprinos no semi-árido. Ciência e Agrotecnologia, v.29, p.177-184, 2005.

Souza, E. J. O.; Guim, A.; Batista, A. M. V.; Albuquerque, D. B. de; Monteiro, C. C. F.; Zumba, E. R. de F.; Torres, T. R. Comportamento ingestivo e ingestão de água em caprinos e ovinos alimentados com feno e silagem de Maniçoba. Revista Brasileira de Saúde Produção, v.11, p.1056-1067, 2010.

Thom, E. C. The discomfort index. Weatherwise, v.12, p.5760, 1959. 